ECCOMAS

Proceedia
COMPDYN 2017

$6^{\text {th }}$ ECCOMAS Thematic Conference on Computational Methods in Structural Dynamics and Earthquake Engineering M. Papadrakakis, M. Fragiadakis (eds.) Rhodes Island, Greece, 15-17 June 2017

\title{
GROUND-BORNE VIBRATIONS DUE TO RAILWAY TRAFFIC IN URBANIZED AREAS: A NUMERICAL STUDY ABOUT TRAFFIC IN TRENCH CROSS-SECTIONS
}

\author{
Alexandre Pinto ${ }^{1}$, Pedro Alves Costa $^{2}$, Aires Colaço ${ }^{2}$, Patrícia Lopes ${ }^{1,2}$ and \\ Mohammed Hussein ${ }^{3}$ \\ ${ }^{1}$ Construct-FEUP, University of Porto \\ Rua Dr. Roberto Frias, 4200-465 Porto, Portugal \\ e-mail: \{amgcpinto, pacosta, aires\}@fe.up.pt \\ ${ }^{2}$ ISEP, Polytechnic Institute of Porto \\ Rua Dr. Roberto Frias, 4200-465 Porto, Portugal \\ e-mail: cpl@isep.ipp.pt \\ ${ }^{3}$ Department of Civil and Architectural Engineering, University of Qatar \\ P.O. Box 2713, Doha, Qatar \\ e-mail: mhussein@qu.edu.qa
}

Keywords: Railway engineering; Trench-cross section; 2.5D FEM-PML; Numerical study; Ground-borne vibrations.

\begin{abstract}
Modern cities require efficient mass transportation systems like subway and railway networks. Due to the lack of available space and also due to environmental concerns, it is usually preferable to use the underground space to construct such kind of infrastructures. In this context, several railway lines run in trench cross-sections in urbanized regions. This option permits to save space, allowing reducing the distance between railway lines and existing buildings. Due to that reduced distance, nearby buildings are exposed to relevant levels of vibrations that can annoys their inhabitants. In the present paper a numerical investigation about the dynamic aspects related with wave propagation due to railway traffic in trench cross-sections is presented. For that purpose, a 2.5D FEM-PML formulation is adopted for the simulation of the main system (track-retaining structure-ground), while the rolling stock is simulated by a multi-body approach. A reference scenario is previously presented, being followed by a parametric study where the influence of the geotechnical properties of the ground was analyzed.
\end{abstract}




\section{INTRODUCTION}

Last decades were marked by an increasing of world population, accompanied by a change in its distribution. As matter of fact, accordingly to the United Nations, in 2050 urban world population will be twice of the population living in rural areas [1] which will present a new set of challenges for the management and planning of those highly populated regions. Facing the reality summarized above, the implementation of railway infrastructure projects arises as a natural option for developing an efficient, environmentally friendly and economic mass transportation system. However, some drawbacks can be figured out to the implementation of railway infrastructures as for instance the annoyance of surrounding inhabitants due to vibrations and noise elicited by railway traffic $[2,3]$. Recent research over the topic allowed stablishing a consolidated pattern of behavior of the physical phenomena [4]: i) the train-track interaction mechanism gives rise to the source of excitation; ii) the energy is transferred to the surrounding ground and travels as elastic waves; iii) the vibrations can impinge nearby structures giving rise to annoyance of inhabitants $[5,6]$. Following this main pattern of behavior, several studies have been done regarding surface railway lines, deserving a special reference the studies conducted by the research group of K.U Leuven [7-9], by Alves Costa et al. [10-13] and by Kouroussis et al [14], among others. Despite the huge research effort putted on the topic of vibrations induced by surface and underground railway infrastructures, all the studies were been confined to those classical cross-section configurations, i.e., surface lines or underground lines. However, in urbanized regions it is often to found a third type of cross-section configuration: the trench cross-section, as can be seen in Figure 1.

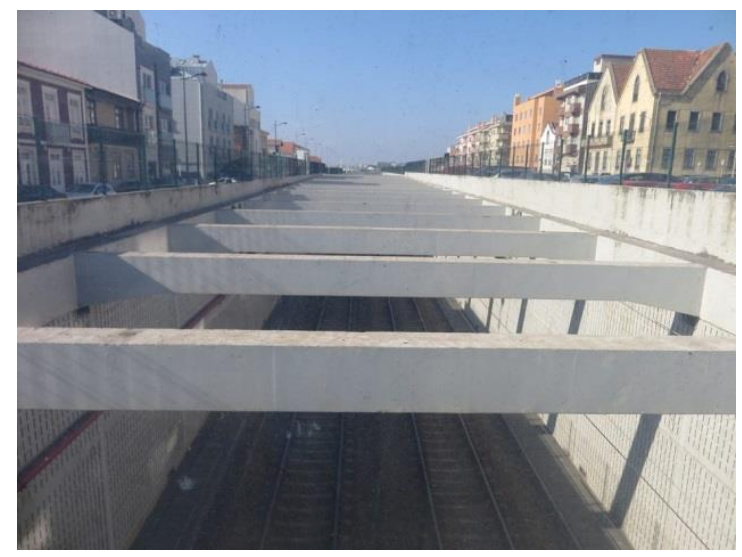

Figure 1 - Railway line along a trench: Espinho, Portugal

The present paper aims to give a contribution to the state of art about ground borne vibrations due to railway traffic, in the precise case of railway infrastructures running in trench cross-sections, i.e., the railway track develops along an excavation supported by propped diaphragm walls, as depicted in Figure 1. To achieve this objective, a numerical study is developed using a 2.5D FEM-PML model, previously developed by the authors [15], is adopted.

\section{BRIEF DESCRIPTION OF THE NUMERICAL APPROACH}

The numerical approach used on the present studies was previously presented by Lopes et al. [16, 17]. From the numerical point of view, the problem can be divided into two main domains: the stand-still domain corresponding to the ground and the moving 
domain, corresponding to the rolling stock. Taking this into account, a sub-structuring approach was followed, being the global model constituted by 2 sub-models, as schematically depicted on Figure 2.

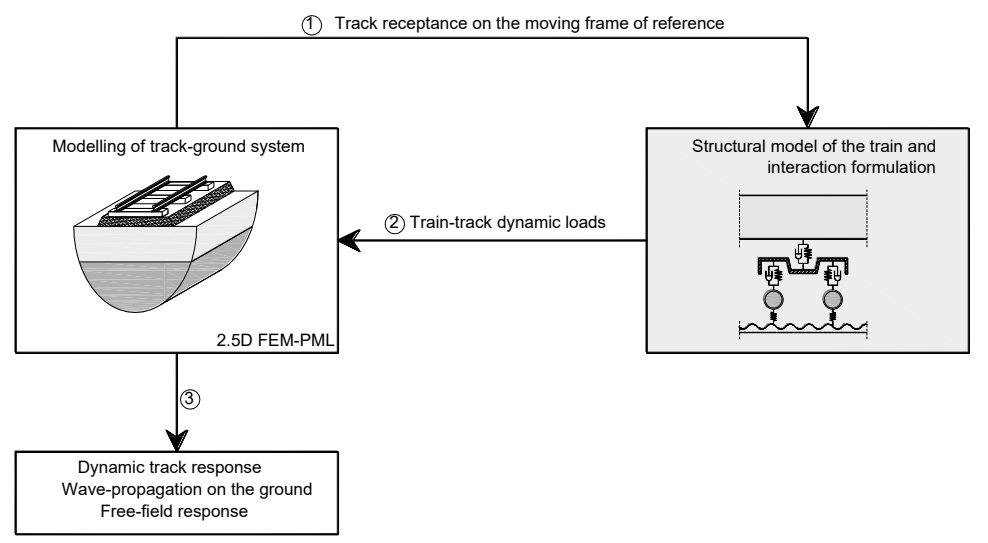

Figure 2 - Schematic representation of the model

Transportation infrastructures, such as roads, railways tracks, pipes, can be often assumed as infinite and longitudinally invariant structures. In such conditions, if the assumption of linear response can be faced as reasonable, it is possible to achieve the solution of the $3 \mathrm{D}$ wave propagation through the system by a $2.5 \mathrm{D}$ approach, where the equilibrium equations are formulated on the wavenumber-frequency domain. This approach takes hand of the Fourier transformation regarding the railway track development direction and, by that reason, only the cross-section needs to be discretized. In the present study a 2.5D finite element approach is followed, since it allows dealing easily with complex geometries. However a PML technique is needed to avoid the spurious wave reflection in the artificial boundaries. Following the $2.5 \mathrm{D}$ FEM-PML approach and after the assemblage of the equations of each individual element, the equilibrium condition is established by the following equation:.

$$
\left\{\left[K_{F E M}^{g}\left(k_{1}\right)\right]+\left[K_{P M L}^{g}\left(k_{1}, \omega\right)\right]-\omega^{2}\left(\left[M_{F E M}^{g}\right]+\left[M_{F E M}^{g}\left(k_{1}, \omega\right)\right]\right)\right\} u_{n}\left(k_{1}, \omega\right)=p_{n}\left(k_{1}, \omega\right)
$$

Where $k_{1}$ is the wavenumber, $\omega$ is the frequency, $u_{n}$ is the vector of nodal displacements is the transformed domain, $p_{n}$ is the vector of external nodal loads in the transformed domain. The matrices $\left[K_{F E M}^{g}\right]$ and $\left[K_{P M L}^{g}\right]$ are the global stiffness matrices of the FEM domain and of the PML domain, respectively, while $\left[M_{F E M}^{g}\right]$ and $\left[M_{P M L}^{g}\right]$ are the corresponding global mass matrices.

The dynamic excitation provided by the train passage can be divided into two distinct mechanisms: i) the quasi-static mechanism; ii) the dynamic mechanism. Regarding the first, its solution is trivial since it corresponds to the movement of the distribution of the dead weight of the train distributed by its axles. On the other hand, the dynamic mechanism arises from the generation of inertial forces on the train due to the traintrack interaction. These inertial effects can be due to different sources, as for instance the track unevenness. Adopting a frequency domain representation of the unevenness, the dynamic interaction loads of each wheelset are given by:

$$
\mathrm{p}(\Omega)=-\left(F+F^{H}+A\right)^{-1} \Delta u(\Omega)
$$

where $F$ is the train compliance at the contact points with the track, $F^{H}$ represents the contact stiffness between train-track, $A$ is the compliance matrix of the track and $\Omega$ is the driving frequency, i.e., the wheelset oscillation frequency resulting from the 
unevenness with a wavelength $\lambda_{\text {irre }}, \Omega=\frac{2 \pi c}{\lambda_{\text {irre }}}$ ). Matrix $F$ can be obtained from simple vehicle model, where only the unsprung masses are taken in account in accordance with Colaço et al.[18].

\section{CASE STUDY}

\subsection{General description}

The selected case study corresponds to a railway line with longitudinal development along a trench cross section. Figure 3 gives an overview of the problem geometry and configuration. As can be seen, the railway track develops between two diaphragm walls connected by an upper strut and by a bottom slab. On the other hand, the material properties are exposed in Table 1. Red dots in Figure 3a represent the receivers points considered for the numerical study.

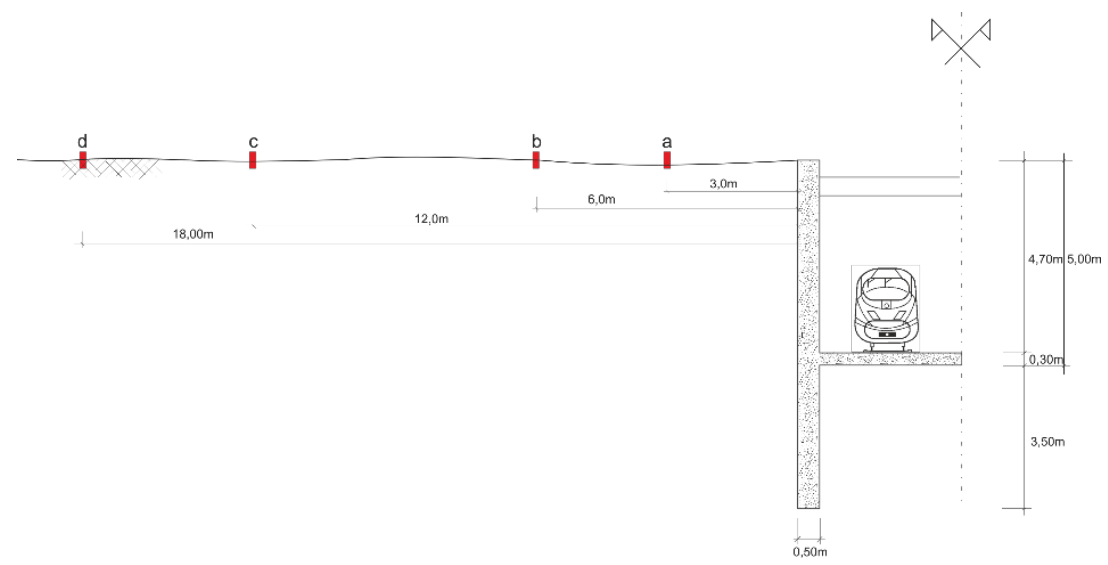

a)

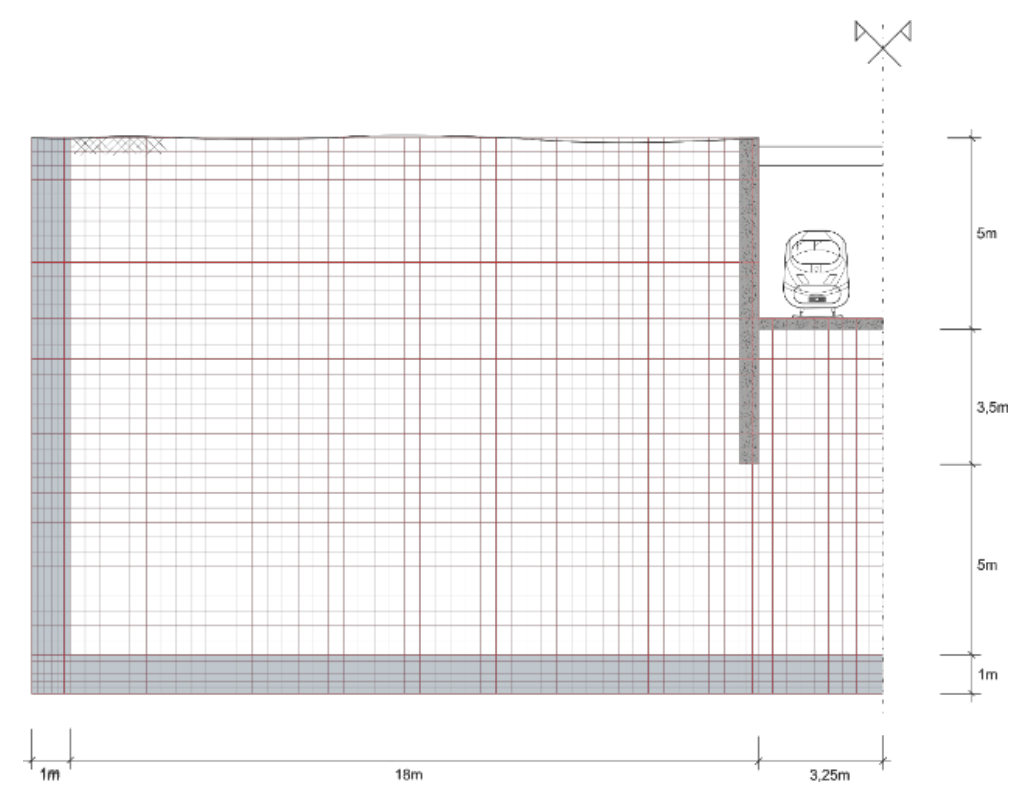

b)

Figure $3-$ a) Schematic section with the receivers points in red; b) transversal section discretized by finite elements. 
Due to symmetric condition of the problem, just half of the cross-section was discretized, being the PML's layers in accordance with this assumption. In order to achieve a viable finite element mesh, the practical rule-of-thumb to limit finite element dimension to $1 / 6$ of the shorter wavelength was followed. Considering shear waves propagating at $250 \mathrm{~m} / \mathrm{s}$ and the maximum frequency of $100 \mathrm{~Hz}$, the finite element size was limited to $40 \mathrm{~cm}$.

Table 1 - Material properties assumed to the cross section.

\begin{tabular}{ccccc}
\hline Materials & $\mathrm{E}(\mathrm{kPa})$ & $\xi[-]$ & $v[-]$ & $\rho\left(\mathrm{Kg} / \mathrm{m}^{3}\right)$ \\
\hline Soil layer & 329062.5 & 0.04 & 0.35 & 1950 \\
\hline Earth Retaining Wall & $3.00 \mathrm{E}+7$ & 0.03 & 0.15 & 2500 \\
\hline Bottom Slab & $3.00 \mathrm{E}+7$ & 0.03 & 0.15 & 2500 \\
\hline
\end{tabular}

In what concerns to the railway track, a STEDEF solution, resting in the bottom slab, was adopted. The geometry and track mechanical properties are depicted in Figure 4.

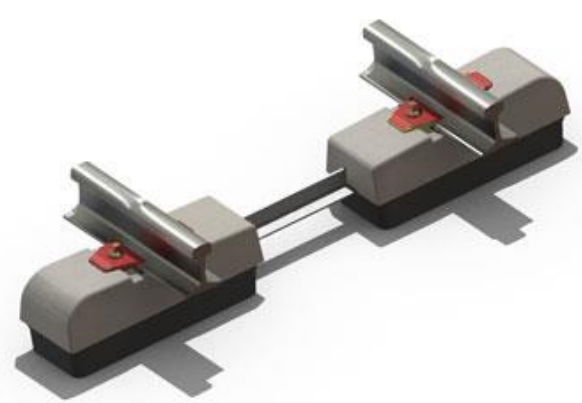

a)

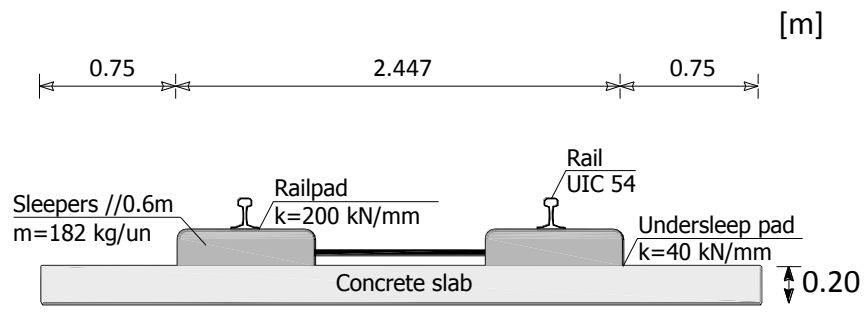

b)

Figure 4-STEDEF railway track: a) schematic representation; b) properties adopted.

For the rolling stock, a 446 series suburban type train, at a running speed of $25 \mathrm{~m} / \mathrm{s}$, was considered. The geometry and the static loads for this train are presented in Figure 5. The mass of $1500 \mathrm{~kg}$ was assumed for each wheelset (unsprung mass).

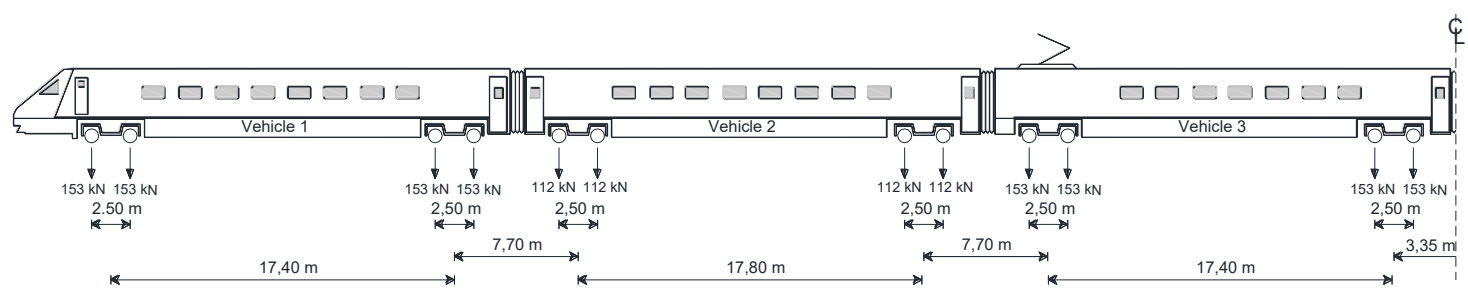

Figure 5 - Suburban 446 series train

A synthetic unevenness profile was generated from FRA PSD function, in correspondence with Class 3 (REF). Wavelengths between $0.3 \mathrm{~m}$ and $9.26 \mathrm{~m}$ were considered, in order to obtain a train excitation frequency range between $2.7 \mathrm{~Hz}$ and 80 $\mathrm{Hz}$.

\subsection{Analysis for point load}

The parametric study was performed in two distinct stages, the first one, a preliminary stage, where the excitation is provided by a unitary stand-still load with variable frequency applied directly in the bottom slab of the system. For this analysis, 
the railway track was not considered. The vertical displacement transfer functions for the receiver points depicted in Figure 3 a) are shown in Figure 6.

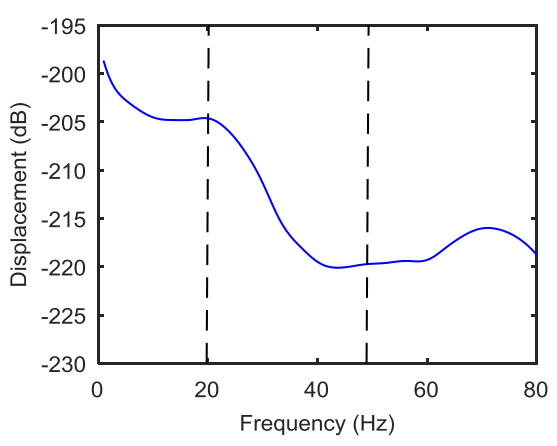

a)

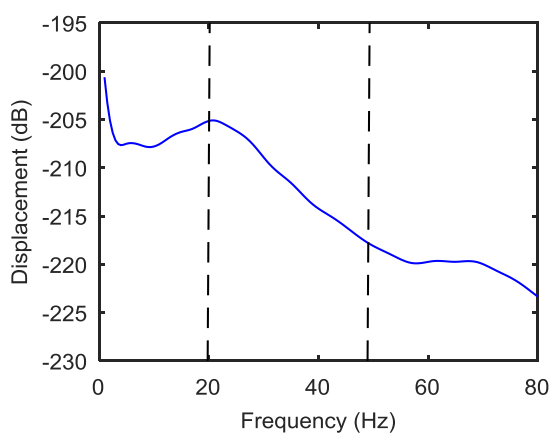

c)

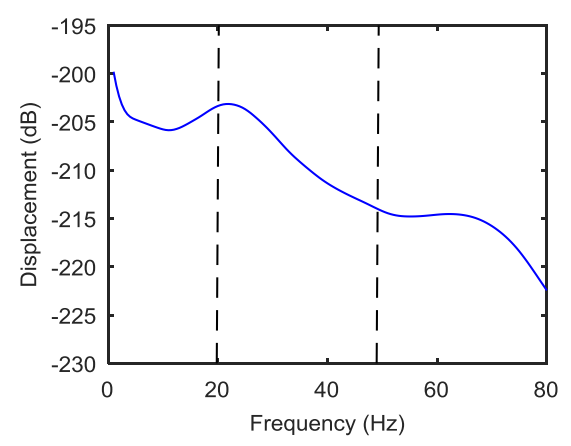

b)

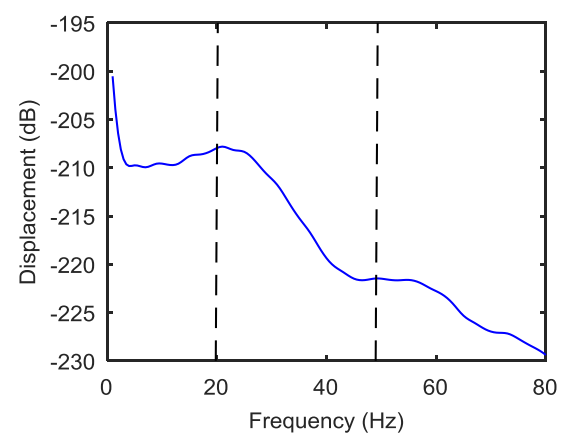

d)

Figure 6- Displacement obtained in the frequency domain for: a) $3 \mathrm{~m}$; b) $6 \mathrm{~m}$; c) $12 \mathrm{~m}$; d) $18 \mathrm{~m}$.

An overview of the results depicted in Figure 6 allows to conclude that there is a strong attenuation in the higher frequency range when the distance source-receiver increase. This effect is mainly due to material damping which effect is more evident with the increasing of the frequency. Nevertheless, a more detailed analysis of the results show the existence of an amplification zone registered between the $6 \mathrm{~m}$ and the $12 \mathrm{~m}$ point, particularly noted for a range of frequencies between 20 and $50 \mathrm{~Hz}$. This can be explained if the geometric characteristics of the transversal section were attended, being easily understood that the vibrations, have to steer round the buried part of the diaphragm wall, leaving the zone close to the retaining wall free from their action.

Independently of the receiver point location, the transfer functions depicted in Figure 6 show a specific peak of the displacement response, obtained for frequencies around $25 \mathrm{~Hz}$. The occurrence of this resonant effect can be explained through a simple analogy to a single degree oscillator, where the mass is given by the mass of the walls and bottom slab and the stiffness is provided by the ground. Actually, a frequency of 25.9 $\mathrm{Hz}$ is obtained from the following equation:

$$
f_{n}=\frac{1}{2 \pi} * \sqrt{\frac{K}{M}}
$$

where the static stiffness $\mathrm{K}$ is evaluated for static conditions $\left(k_{1}=0\right)$. 


\subsection{D Analysis for a train passage}

Since the main goal of the study is to give a contribution for the knowledge about vibration effects induced by railway traffic in trench cross-sections, the effects induced by the passage of the train at a speed of $25 \mathrm{~m} / \mathrm{s}$ is here considered. Figure 7 depicts the vertical velocity time records for different locations at the ground surface. As can be seen, there is an amplification of the peak vertical velocity at points located at $6.0 \mathrm{~m}$ and $12.0 \mathrm{~m}$ when compared with the results observed for the point located $3.0 \mathrm{~m}$ away from the retaining wall. This effect agrees well with the explanation presented in the section above, being clear that the wall acts as a partial shield for a region close to the trench.

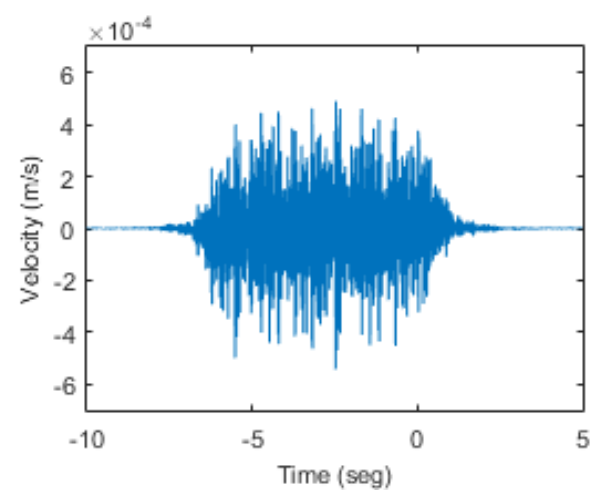

a)

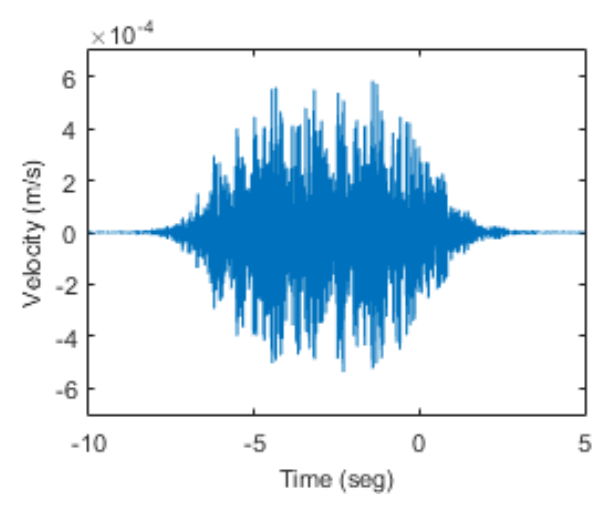

c)

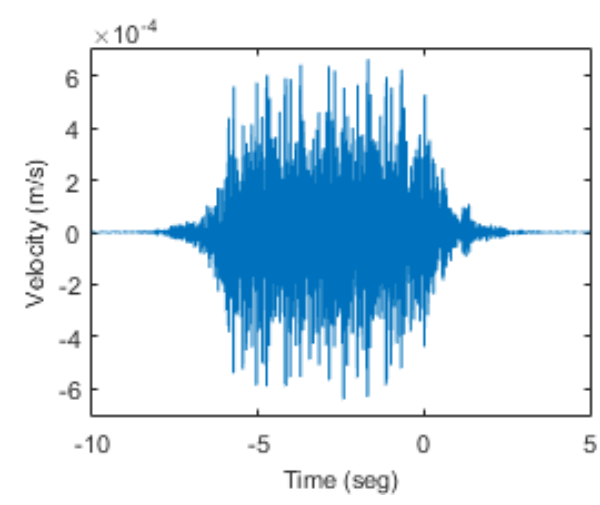

b)

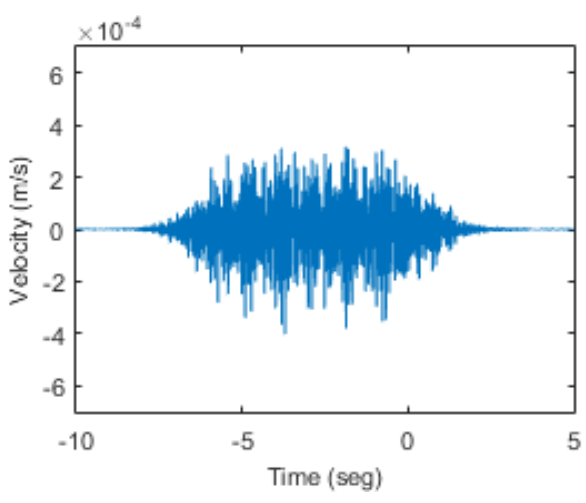

d)

Figure 7 - Vertical velocity on time domain for: a) $3 \mathrm{~m}$; b) $6 \mathrm{~m}$; c) $12 \mathrm{~m}$; d) $18 \mathrm{~m}$.

Figure 8 shows the same results as Figure 7, but now in the frequency domain through one-third octave bands. From this representation it is clear that the response in the points located at $6 \mathrm{~m}$ and $12 \mathrm{~m}$ is amplified in the frequency range between $25 \mathrm{~Hz}$ and $60 \mathrm{~Hz}$ when the results are compared with those obtained for the point located $3 \mathrm{~m}$ away from the retaining wall. On the other hand, the response of point located $18 \mathrm{~m}$ away from the wall is attenuated in whole frequency range, but with more emphasis in the higher frequencies denoting the impact of the material damping. 


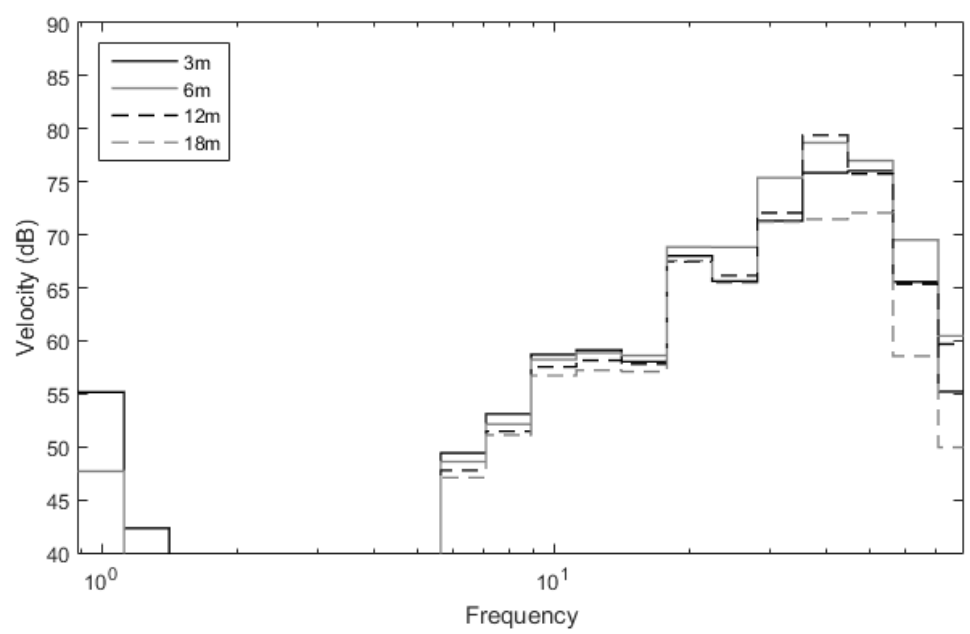

Figure 8 - Velocity registered on frequency domain for the points $: 3 \mathrm{~m}, 6 \mathrm{~m}, 12 \mathrm{~m}, 18 \mathrm{~m}$.

\subsection{Influence of the Geotechnical Profile}

It is well known that the geotechnical conditions play an important role on the vibration fields generated by traffic vibrations. To investigate the impact of the geotechnical profile on the present case study, two variant scenarios where considered: i) a homogeneous ground with a stiffness four times larger than the reference scenario; ii) A layered ground scenario, where the a layer with same properties as the reference scenario is overlaying a stiffer half-space (see Figure 9).

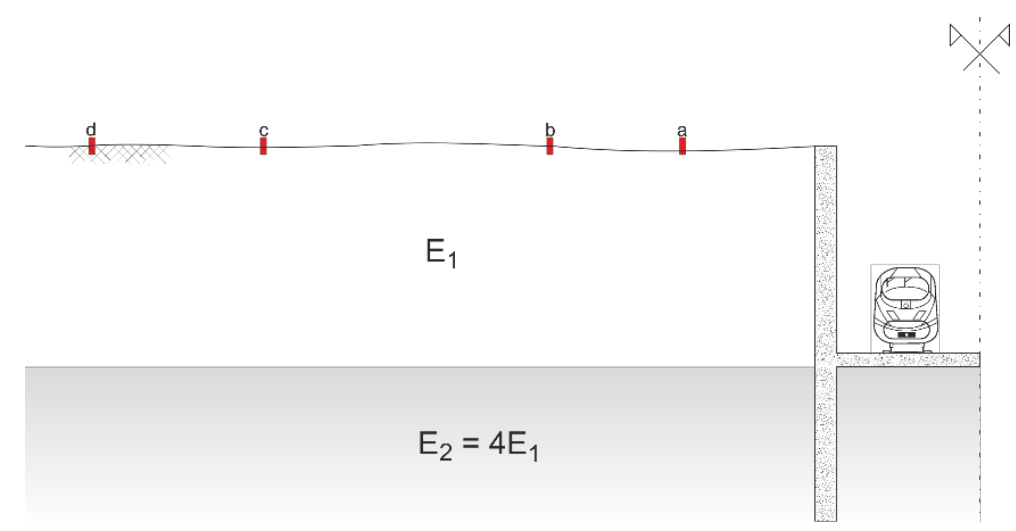

Figure 9 - Heterogeneous scenario with a stiffer substratum coincident with the bottom slab

Figure 10 shows the vertical displacement transfer functions for the distinct receiver locations and for the different scenarios under analysis due to a stand-still point load located in the bottom slab of the retaining structure. A global overview of the results show that for frequencies up to $30 \mathrm{~Hz}$ there is an attenuation of the vibration level with the increase of the soil stiffness. Moreover, for the low frequency range (up to $7 \mathrm{~Hz}$ ), the dynamic response of the layered ground is very similar to that one obtained with the stiffer ground, showing that the dynamic response is controlled by the deeper layer properties. For the other range of frequencies evaluated, it is observed an approximation of the response pattern for the two homogenous cases. This pattern of the dynamic response, more evident in the points located at larger distance from the wall, is due to the fact that the material damping effect is more pronounced in the softer soil since for 
the same frequency shorter are the propagated wavelengths. This damping effect partially balances the benefit induced by the increase of ground stiffness.

Comparing now the response of the layered system with the homogeneous ground scenarios, it is clear that the pattern of response is much more complex due to the wave reflection in the layers boundary. Nevertheless, for the frequencies up to $30 \mathrm{~Hz}$, the vertical displacements of the layered system are bounded by the values obtained for the homogenous scenarios.

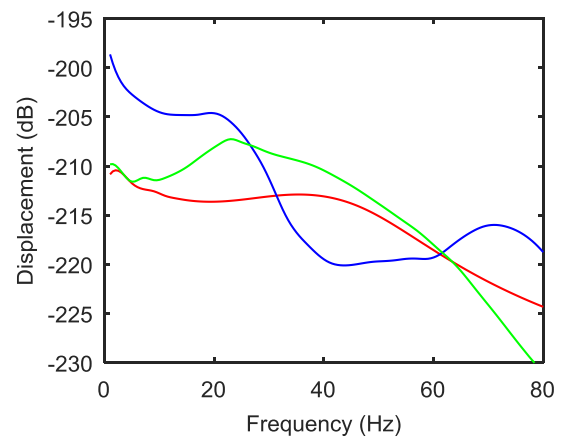

a)

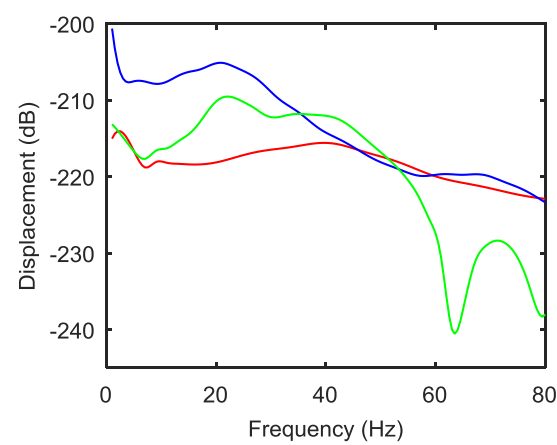

c)

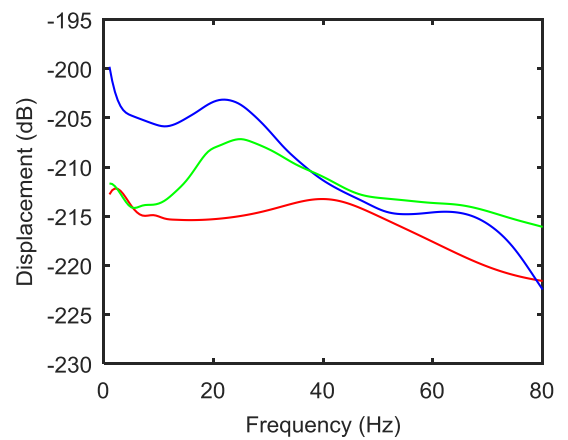

b)

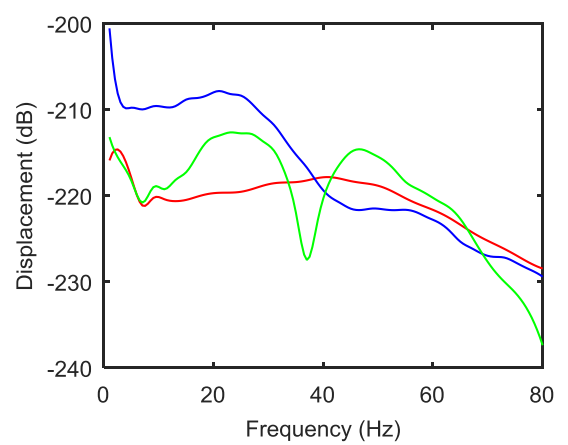

d)

Figure 10- Displacement registered on the transform domain for: a) 3m; b) 6m; c) 12m; d) 18m. (Blue - case study scenario, Red - Homogeneous with stiffer ground; Green - Heterogeneous scenario)

If instead of a point load excitation, the passage of the train is considered, similar conclusions are achieved, as can be seen from the Figure 11, where the vertical velocity in observation points is depicted in terms of one-third octave band. As expected from the previous analysis, for the lower frequency range, the dynamic response of the layered ground is similar to that one observed for the stiffer homogeneous soil. However, in the frequency range around $60 \mathrm{~Hz}$, the dynamic response of the layered ground is very similar to that one obtained for the stiffer ground and larger than the obtained for the softer one. This aspect justified that the peak vertical velocity can be larger in the stiffer scenarios when compared with the softer case, as can be seen in Figure 12, where the vertical velocity time history is presented for the different points under analysis. Comparing the different time records depicted in the figure it is possible to see that the difference in the peak velocities is attenuated with the increase of the distance source-receiver. 


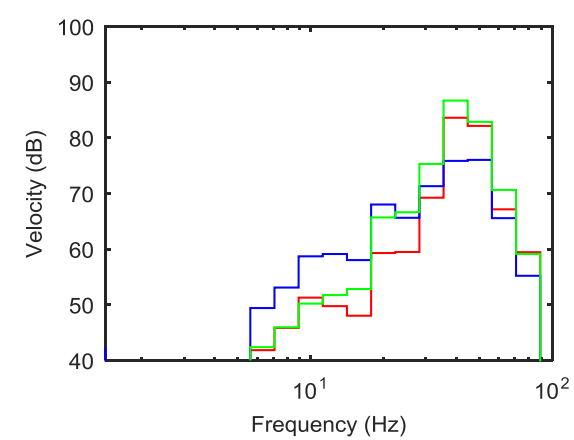

a)

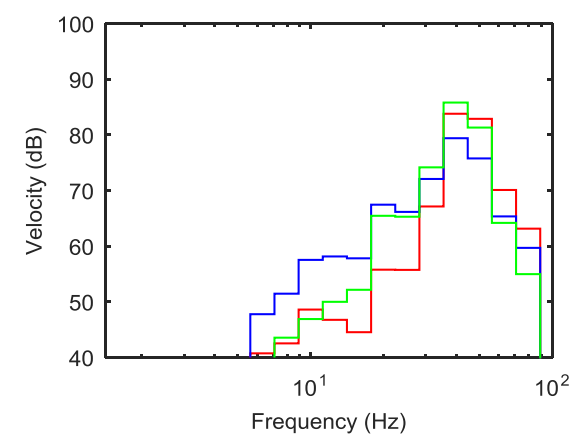

c)

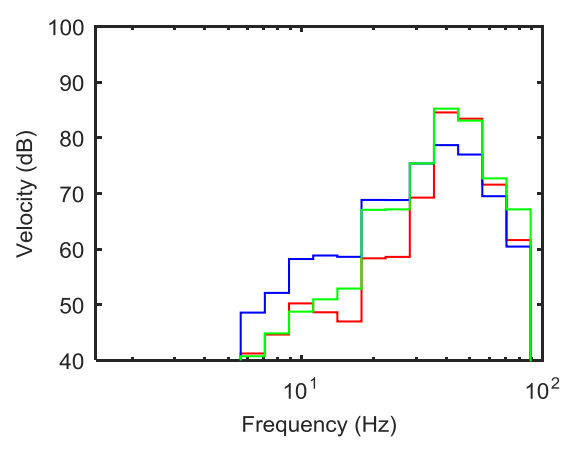

b)

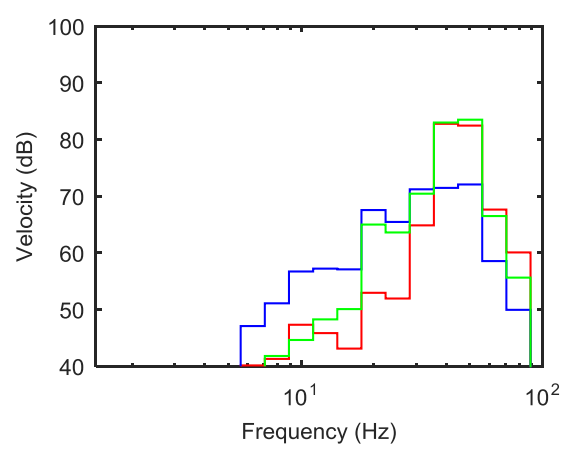

d)

Figure 11 - Velocity registered on the transform domain for a) 3m; b) 6m; c) 12m; d) 18m.; (Blue case study scenario, Red - Homogeneous with stiffer ground; Green - Heterogeneous scenario)

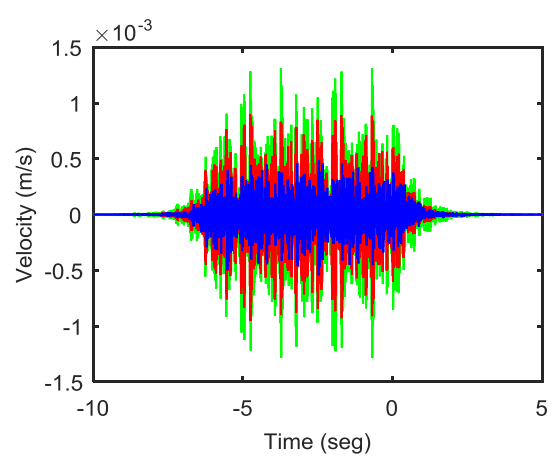

a)

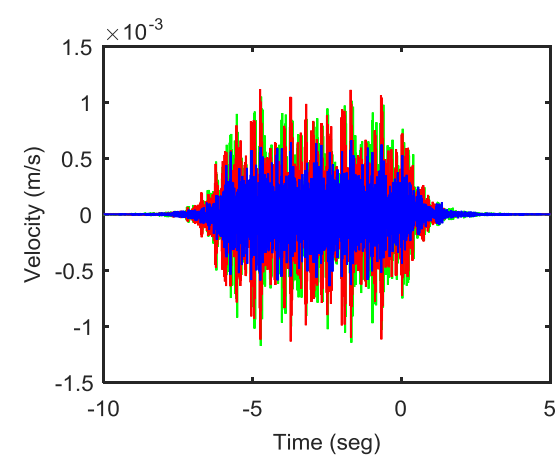

b)

Figure 12 - Velocity registered on the time domain for; a) 3m; b) 6m. (Blue - Case study scenario; Red - Homogeneous with stiffer ground; Green - Heterogeneous scenario)

\section{Conclusions}

In this paper, the authors presented a study about vibrations induced by railway traffic in a trench cross-section. For that task, a numerical model based in a substructuring approach was considered, where a 2.5D FEM-PML approach was used to compute the track-ground response. After the global model presentation, a case study was presented. In this preliminary study, it was possible to compute a complex dynamic 
response, which being governed by several parameters as the geometry of the crosssection and the ground properties. It was found that the larger vibration levels are not found in the vicinity of the diaphragm walls, but at some distance from it due to the partial shield effect induced by the diaphragm wall. In order to deeper understand the behavior of the global system, an additional studied was conducted, where a heterogeneous ground profile with a stiffer substratum was considered. In this scenario, there is a complex trend of the ground response with the increase of the distance to the railway track due to the multiple reflections that occur in the boundary between the two layers. Nevertheless, it was possible to identify that for frequencies up to $30 \mathrm{~Hz}$, the dynamic response of the layered scenario is bounded by the response of the homogenous half-space solution assuming the properties of each layer.

\section{ACKNOWLEDGEMENTS}

This work was financially supported by: Project POCI-01-0145-FEDER-007457 - CONSTRUCT Institute of R\&D in Structures and Construction funded by FEDER funds through COMPETE2020 Programa Operacional Competitividade e Internacionalização (POCI) - and by national funds through FCT - Fundação para a Ciência e a Tecnologia: Project PTDC/ECM-COM/1364/2014 and Individual Grant SFRH/BD/101044/2014.

\section{REFERENCES}

[1] D.o.E.a.S.A. United Nations, Population Division World Urbanization Prospects: The 2014 Revision, Highlights (ST/ESA/SER.A/352), in, 2015.

[2] M.G. Smith, I. Croy, M. Ögren, K. Persson Waye, On the Influence of Freight Trains on Humans: A Laboratory Investigation of the Impact of Nocturnal Low Frequency Vibration and Noise on Sleep and Heart Rate, PLoS ONE, 8 (2013) e55829.

[3] I. Croy, M.G. Smith, K. Waye, Effects of train noise and vibration on human heart rate during sleep: an experimental study, BMJ Open, doi:10.1136/bmjopen-2013-002655 (2013).

[4] C. Lai, A. Callerio, E. Faccioli, V. Morelli, P. Romani, Prediction of railway-induced ground vibrations in tunnels Journal of Vibration and Acoustics, 127 (2005) 503-514.

[5] P. Fiala, S. Gupta, G. Degrande, F. Augusztinovicz, A Numerical Model for Re-radiated Noise in Buildings from Underground Railways, in: B. Schulte-Werning, D. Thompson, P.-E. Gautier, C. Hanson, B. Hemsworth, J. Nelson, T. Maeda, P. Vos (Eds.) Noise and Vibration Mitigation for Rail Transportation Systems, Springer Berlin Heidelberg, 2008, pp. 115-121.

[6] A. Colaço, P. Alves Costa, P. Amado Mendes, L. Godinho, Prediction of vibrations and reradiated noise due to railway traffic. A comprehensive model based in on a FEM-MFS approach, Journal of Vibration and Acoustics, (under review) (2017).

[7] G. Lombaert, G. Degrande, Ground-borne vibration due to static and dynamic axle loads of InterCity and high-speed trains, Journal of Sound and Vibration, 319 (2009) 1036-1066.

[8] G. Lombaert, G. Degrande, J. Kogut, S. François, The experimental validation of a numerical model for the prediction of railway induced vibrations, Journal of Sound and Vibration, 297 (2006) 512-535.

[9] P. Galvín, S. François, M. Schevenels, E. Bongini, G. Degrande, G. Lombaert, A 2.5D coupled FE-BE model for the prediction of railway induced vibrations, Soil Dynamics and Earthquake Engineering, 30 (2010) 1500-1512. 
[10] P. Alves Costa, R. Calçada, A. Cardoso, Track-ground vibrations induced by railway traffic: In-situ measurements and validation of a 2.5D FEM-BEM model, Soil Dynamics and Earthquake Engineering, 32 (2012) 111-128.

[11] P. Alves Costa, R. Calçada, A. Silva Cardoso, Track-ground vibrations induced by railway traffic, in: L. Sousa, M. Fernandes, E. Vargas, R. Azevedo (Eds.) Applications of Computational Mechanics in Geotechnical Engineering,, Balkema, 2012, pp. (book under editing).

[12] P. Alves Costa, R. Calçada, A. Silva Cardoso, Ballast mats for the reduction of railway traffic vibrations. Numerical study, Soil Dynamics and Earthquake Engineering, 42 (2012) 137-150.

[13] P. Alves Costa, R. Calçada, A. Silva Cardoso, Vibrations Induced by Railway Traffic: Prediction, Measurement and Mitigation in: R. Calçada, H. Xia (Eds.) Traffic Induced Environmental Vibrations and Controls: Theory and Application, Nova, 2013, pp. 49-89.

[14] G. Kouroussis, O. Verlinden, C. Conti, Ground propagation of vibrations from railway vehicles using a finite/infinite-element model of the soil, Journal of Rail and Rapid Transit, 223 (2009) 405-413.

[15] P. Lopes, P. Alves Costa, R. Calçada, A. Silva Cardoso, Numerical Modeling of Vibrations Induced in Tunnels: A 2.5D FEM-PML Approach, in: H. Xia, R. Calçada (Eds.) Traffic Induced Environmental Vibrations and Controls: Theory and Application, Nova, 2013, pp. 133-166.

[16] P. Lopes, P. Alves Costa, R. Calçada, A. Silva Cardoso, Influence of soil stiffness on vibrations inside buildings due to railway traffic: numerical study, Computers \& Geotechnics, 61 (2014) 277-291.

[17] P. Lopes, P. Alves Costa, M. Ferraz, R. Calçada, A. Silva Cardoso, Numerical modelling of vibrations induced by railway traffic in tunnels: from the source to the nearby buildings, Soil Dynamics and Earthquake Engineering, 61-62 (2014) 269-285.

[18] A. Colaço, P.A. Costa, D.P. Connolly, The influence of train properties on railway ground vibrations, Structure and Infrastructure Engineering, 12 (2016) 517-534. 